Article

\title{
Eco-Efficient Hybrid Cements: Pozzolanic, Mechanical and Abrasion Properties
}

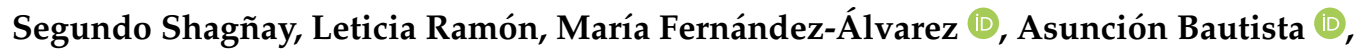 \\ Francisco Velasco (D) and Manuel Torres-Carrasco * (D) \\ Materials Sciences and Engineering Department-IAAB, University Carlos III of Madrid, Avda. Universidad 30, \\ Leganés, 28911 Madrid, Spain; sshagnay@ing.uc3m.es (S.S.); 100330615@alumnos.uc3m.es (L.R.); \\ mfalvare@ing.uc3m.es (M.F.-Á.); mbautist@ing.uc3m.es (A.B.); fvelasco@ing.uc3m.es (F.V.) \\ * Correspondence: matorres@ing.uc3m.es; Tel.: +34-91-6248374
}

Received: 26 November 2020; Accepted: 12 December 2020; Published: 16 December 2020

\begin{abstract}
One of the most polluting industries is the cement industry and, for this reason, alternative lines of research recommend the use of substitute materials for traditional Portland cement. This study proposes the use of industrial (slag and fly ash) and ceramic wastes for the total or partial replacement of Portland cement in the manufacturing of both alkaline-activated and hybrid cements. To carry out this study and evaluate the behavior of the proposed materials, different mortars were manufactured: Portland cement (CEM I), two alkaline-activated slag systems and six hybrid systems, with an $80-20 \%$ waste-to-Portland-cement ratio for all the proposed wastes. An assessment of the pozzolanic activity was carried out for the different materials. The behavior of all the systems regarding mechanical resistance and durability to abrasion was studied. All the proposed materials, especially those with ceramic wastes, showed pozzolanic activity and suitable characteristics for use in the manufacturing of alternative cements. The mortar made of slag activated with waterglass presented the highest mechanical strength and lowest porosity, but the hybrid materials presented competitive results. After being subjected to the Böhme abrasion test, their effectiveness as substitutes for Portland cement is reiterated, some of them improving their durability to wear.
\end{abstract}

Keywords: abrasion behavior; alkali-activated materials; hybrid materials

\section{Introduction}

Over the last century, the temperature of the Earth's surface has increased by around $1{ }^{\circ} \mathrm{C}$, sea levels have risen by about $19 \mathrm{~cm}$ on average globally and the concentration of $\mathrm{CO}_{2}$ in the atmosphere is now the highest in the last 800,000 years. All of this is mainly a consequence of industrial activity and the waste it produces. The cement industry is among the most highly polluting industries, being the source of approximately $8-9 \%$ of the world's $\mathrm{CO}_{2}$ emissions [1]. Portland cement is the most widely used cementing material worldwide, but its production involves not only the landscape pollution produced by the extraction of raw material from quarries and during the chemical manufacturing process but also the large amounts of energy consumed by the furnaces used (temperatures above $1400{ }^{\circ} \mathrm{C}$ ). For this reason, the need arises to develop alternative materials to Portland cement to help reduce the level of emissions as well as energy consumption [2-5].

An alternative line of research to Portland cement is the use of different industrial wastes from other sectors such as thermal power plants (fly ash) [6,7], the steel industry (blast furnace slag) $[8,9]$ or the ceramic industry [10-12]. These wastes, after an alkaline activation process, generate new, aluminosilicate-rich, alternative materials to Portland cement called geopolymers or alkaline-activated materials. Their mechanical and durable properties can be similar or even superior to those presented by Portland cement materials [6], depending on the optimization of their formulation and manufacturing 
procedure. This alkaline activation reaction occurs between aluminosilicates (present in industrial wastes) and alkaline solutions (such as sodium silicate or $\mathrm{NaOH}$ ).

However, regarding the different aluminosilicates used for alkaline activation, it is necessary to search for other materials susceptible to activation for use as active pozzolans in cementitious systems $[11,13,14]$. In this sense, wastes from the ceramic sector become important. High production in the ceramic industry generates around 50,000 $t$ of fired waste annually. A large part of this waste is indeed reused in the manufacturing process, defending the condition of zero discharge. This reuse process requires special facilities, involving high maintenance and management costs not normally offset by reducing the consumption of raw materials. Due to this, in many cases, this waste is deposited in controlled landfills. These cooked residues are chemically inert but generate considerable environmental impact and, therefore, their study is proposed for use as alternative pozzolanic materials in the manufacturing of cement [12]. The incorporation of these residues in the manufacturing of cement could offer numerous advantages such as the reduction of clinker content, with the consequent reduction of the negative effects generated by its production; the revaluation of these ceramic residues; and, on many occasions, the improvement of the properties of the cements obtained.

Some of the most important characteristics of these geopolymers are high mechanical resistance and low heats of hydration. They possess high durability to aggressive physical and chemical agents, resistance to high temperatures [15], as well as resistance to freeze-thaw cycles [16-18], among other properties. However, alkaline-activated systems have some disadvantages and not all properties are good. In this sense, it is worth highlighting the use of alkaline activators, which are obtained after very expensive and environmentally harmful industrial processes. For instance, the preparation of $1 \mathrm{~kg}$ of sodium silicate emits $1.5 \mathrm{~kg}$ of $\mathrm{CO}_{2}$ into the atmosphere. Therefore, the global and total replacement of Portland cement by any of the possible alkaline-activated cements is practically impossible. In addition, there are numerous problems associated with the chemistry of these systems, such as problems with rheology in pastes, mortars and concrete; problems related to the supply of raw materials; implementation problems in civil works due to the use of activator solutions; and the need to use curing temperatures in some systems (activation of fly ash).

For all this, the need arises to search for alternative cementing materials, both to Portland cement and alkaline-activated systems. In this sense, hybrid cements are a good option [19]. These systems are characterized by the use of a high content of supplementary cementitious materials (SCM), mainly residues between 70 and $80 \mathrm{wt} \%$, so that the use of Portland cement (between 20 and $30 \mathrm{wt} \%$ ) can be minimized. However, although the cement content is low in these systems, it is necessary to incorporate an alkaline activator in their composition, generally in solid form $\left(\mathrm{Na}_{2} \mathrm{SO}_{4}\right.$ is the most used). From a microstructural point of view, the compatibility of the gels formed during the hydration processes of hybrid cements (C-S-H, C-A-S-H and N-A-S-H gels) possesses important consequences from a technological and application point of view, making it a priority line of research worldwide.

On the other hand, it should be noted that there are numerous studies related to the durability of these systems to chemical agents, freeze-thaw, high temperatures, and so on, but there is limited information available on durability to wear in these alkaline-activated and/or hybrid systems. These cementitious materials could be used as floors, tiles, pavements or runways so they can withstand abrasion, scraping and percussion of cars and heavy trucks or even airplanes; therefore, it is crucial to understand their durability to wear. However, although it is one of the most important characteristics to study in construction materials, there are few studies that analyze wear resistance and wear mechanisms in alternative cementitious materials $[20,21]$. To determine the effectiveness of the proposed industrial residues as cementitious materials, it is necessary to carry out this study and evaluate their durability to wear since some of these systems are gaining a high degree of acceptance in various applications.

Therefore, the aim of the present work is to study new materials (hybrid mortars) through the use of different wastes (slag, fly ash and ceramic wastes) to evaluate their use as pozzolanic materials and their durability to abrasion. This study is mainly based on Böhme tests that consist of sliding the mortar against corundum abrasive materials placed on a cast iron wheel under a load. 


\section{Materials and Methods}

\subsection{Materials}

Table 1 shows the chemical composition of the materials used in this work. Conventional Portland cement (Cementos Portland Valderrivas, Madrid, Spain) (CEM I) was used as a reference and for the preparation of the different hybrid cement systems. F-type fly ash (Puentenuevo steam plant, Córdoba, Spain) (ASTM C618-03) and blast furnace slag (Avilés factory, Asturias, Spain) were used as raw materials. In addition, two wastes from the ceramic industry were used for the preparation of hybrid cements. They are residues from the preparation of ceramic wall tiles (labeled as "porous waste") and from the sintering of porcelain tiles (labeled as "porcelain waste"). Both wastes were supplied by Keraben (Keraben, Nules, Spain). The average particle size was determined in all materials (measured using a Mastersizer 200 Hydro2000SM equipment) (Malvern Instruments, Worcestershire, UK, Table 2).

Table 1. Chemical composition by X-ray fluorescence.

\begin{tabular}{cccccccccc}
\hline wt $\%$ & $\mathbf{C a O}$ & $\mathbf{S i O}_{\mathbf{2}}$ & $\mathbf{A l}_{\mathbf{2}} \mathbf{O}_{\mathbf{3}}$ & $\mathbf{M g O}$ & $\mathbf{F e}_{2} \mathbf{O}_{3}$ & $\mathbf{S O}_{3}$ & $\mathbf{K}_{\mathbf{2}} \mathbf{O}$ & $\mathbf{N a}_{\mathbf{2}} \mathbf{O}$ & $\mathbf{L O I} *$ \\
\hline CEM I & 61.8 & 21.5 & 6.6 & $<0.01$ & 2.5 & 5.9 & 1.1 & $<0.014$ & 2.35 \\
Slag & 38.0 & 35.0 & 11.7 & 12.0 & 0.2 & 1.9 & 0.3 & $<0.014$ & 2.10 \\
Fly ash & 4.1 & 46.6 & 28.1 & 0.7 & 17.0 & 1.1 & 1.1 & $<0.014$ & 1.00 \\
Porcelain waste & 2.5 & 64.7 & 21.2 & 0.5 & 2.3 & 0.05 & 1.2 & 8.5 & 1.00 \\
Porous waste & 8.7 & 62.5 & 22.7 & 0.3 & 2.6 & 0.3 & 1.8 & $<0.014$ & 2.00 \\
\hline & & $*$ & &
\end{tabular}

Table 2. Particle size distributions of the different materials studied.

\begin{tabular}{lccccc}
\hline & CEM I & Slag & Fly Ash & Porous Waste & Porcelain Waste \\
\hline $\mathrm{D}_{10}(\mu \mathrm{m})$ & 2.9 & 3.8 & 0.1 & 0.6 & 2.5 \\
$\mathrm{D}_{50}(\mu \mathrm{m})$ & 19.6 & 13.2 & 6.5 & 10.7 & 11.5 \\
$\mathrm{D}_{90}(\mu \mathrm{m})$ & 65.3 & 34.9 & 35.4 & 78.9 & 95.8 \\
\hline
\end{tabular}

Regarding the ceramic wastes, both types present a similar chemical composition similar to the chemical composition of fly ash, with high contents of $\mathrm{SiO}_{2}, \mathrm{Al}_{2} \mathrm{O}_{3}$ and $\mathrm{Fe}_{2} \mathrm{O}_{3}$ and lower $\mathrm{CaO}$ percentages than slag. Therefore, during their activation, they will possibly form a gel similar to the $\mathrm{N}-\mathrm{A}-\mathrm{S}-\mathrm{H}$ type. It should be noted that when comparing both ceramic wastes, the porous material has a higher percentage of $\mathrm{CaO}$ than the porcelain material. Furthermore, porcelain waste shows a very high $\mathrm{Na}_{2} \mathrm{O}$ content compared to the other proposed wastes.

\subsection{Mortar Preparation}

Table 3 summarizes the main composition characteristics of the different systems studied. It should be noted that the mixtures to manufacture the different mortars are based on the following classification:

- Ordinary Portland cement systems (CEM I): a type I 42.5R Portland cement was used and hydrated with water.

- Alkaline-activated materials: these were composed of a subindustrial waste (slag) and activated using alkaline solutions with basic $\mathrm{pH}(\mathrm{pH}>13)$. In this sense, two solutions were used: $4 \mathrm{M}$ $\mathrm{NaOH}$ solution (AAS-N) and a commercial sodium silicate solution (waterglass) with a $\mathrm{SiO}_{2} / \mathrm{Na}_{2} \mathrm{O}$ ratio of 1.2 (AAS-WG).

- Hybrid materials: these mortars were composed of ordinary Portland cement (20 wt \%) and industrial and ceramic wastes (fly ash, blast furnace slag and two ceramic wastes), of which the amount was $80 \mathrm{wt} \%$ Furthermore, in these hybrid systems, a percentage of $\mathrm{Na}_{2} \mathrm{SO}_{4}($ at $3 \%$ and $5 \mathrm{wt} \%$ ) was added to favor the hydration process of the materials. Water was used as the activating solution. 
Table 3. Prepared mortars and activation conditions.

\begin{tabular}{|c|c|c|c|c|c|c|}
\hline System & Name & Waste & $\begin{array}{c}\text { wt } \% \text { of } \\
\text { CEM I }\end{array}$ & $\begin{array}{l}\text { wt } \% \text { of } \\
\text { Waste }\end{array}$ & Activator & $\mathrm{L} / \mathrm{S}$ \\
\hline Portland cement & CEM I & - & 100 & 0 & $\mathrm{H}_{2} \mathrm{O}$ & 0.50 \\
\hline \multirow{2}{*}{$\begin{array}{c}\text { Alkali-activated } \\
\text { materials }\end{array}$} & AAS-N & Slag & 0 & 100 & $4 \mathrm{M} \mathrm{NaOH}$ & 0.50 \\
\hline & AAS-WG & Slag & 0 & 100 & Waterglass & 0.50 \\
\hline \multirow{6}{*}{$\begin{array}{l}\text { Hybrid } \\
\text { materials }\end{array}$} & HFA-3\% & Fly ash & 20 & 80 & $\begin{array}{c}\mathrm{H}_{2} \mathrm{O}+ \\
3 \% \mathrm{Na}_{2} \mathrm{SO}_{4}\end{array}$ & 0.37 \\
\hline & HFA-5\% & Fly ash & 20 & 80 & $\begin{array}{c}\mathrm{H}_{2} \mathrm{O}+ \\
5 \% \mathrm{Na}_{2} \mathrm{SO}_{4}\end{array}$ & 0.37 \\
\hline & HS-3 $\%$ & Slag & 20 & 80 & $\begin{array}{c}\mathrm{H}_{2} \mathrm{O}+ \\
3 \% \mathrm{Na}_{2} \mathrm{SO}_{4}\end{array}$ & 0.42 \\
\hline & HS-5\% & Slag & 20 & 80 & $\begin{array}{c}\mathrm{H}_{2} \mathrm{O}+ \\
5 \% \mathrm{Na}_{2} \mathrm{SO}_{4}\end{array}$ & 0.42 \\
\hline & HWT-5\% & $\begin{array}{l}\text { Porous } \\
\text { waste }\end{array}$ & 20 & 80 & $\begin{array}{c}\mathrm{H}_{2} \mathrm{O}+ \\
5 \% \mathrm{Na}_{2} \mathrm{SO}_{4}\end{array}$ & 0.42 \\
\hline & HРТ-5\% & $\begin{array}{c}\text { Porcelain } \\
\text { waste }\end{array}$ & 20 & 80 & $\begin{array}{c}\mathrm{H}_{2} \mathrm{O}+ \\
5 \% \mathrm{Na}_{2} \mathrm{SO}_{4}\end{array}$ & 0.37 \\
\hline
\end{tabular}

For the preparation of all mortar systems, standardized sand was used, with a 3:1 sand/cementitious material ratio. For each proposed system, $4 \times 4 \times 16 \mathrm{~cm}$ specimens were made at different curing ages (1, 7 and 28 days). It should be noted that, in each evaluated system, a different liquid/solid ratio (L/S) was used that was appropriate for each, but in all cases, the ratio was selected in equal consistency accordance with the UNE-EN 1015-6 standard to appropriately compare the results (values of the diameter of spread of $150 \pm 10 \mathrm{~mm}$ ).

\subsection{Tests Conducted}

The chemical composition of all materials was determined by X-ray fluorescence analysis using a XEPOS Ametek spectrophotometer (Spectro, Kleve, Germany). Structural characterization of the raw materials was performed with the X-ray diffraction (XRD) technique in a Bruker D8 Advance diffractometer (Bruker, Ettlingen, Germany) with $\mathrm{Cu} K \alpha$ radiation at $40 \mathrm{kV}$ and $40 \mathrm{~mA}$. Crystalline phases were identified by comparison with the JCPDS patterns. Fourier transform infrared spectroscopy (FTIR) of samples was performed by the Perkin Elmer Spectrum 100 FTIR spectrometer in transmittance mode in the range of $400-4000 \mathrm{~cm}^{-1}$ by attenuated total reflectance (ATR) of the powders (Perkin Elmer Inc., Waltham, MA, USA).

The pozzolanic activity of the different wastes was assessed with an accelerated chemical method based on the pozzolanicity test for pozzolanic cements recommended in the European legislation [22]. The saturated lime solution (SLS) test was used, which involved placing $1 \mathrm{~g}$ of sample in $75 \mathrm{~mL}$ of a saturated lime solution (SLS) at $40{ }^{\circ} \mathrm{C}$ for a pre-established test time. After the reaction time elapsed, the solutions were filtered, and $0.02 \mathrm{M}$ EDTA was titrated to determine its $\mathrm{CaO}$ concentration. The amount $(\%)$ of lime fixed to the mineral or engineered feldspar was then calculated as the difference between the reference concentration $(17.68 \mathrm{mmol} / \mathrm{L})$ and the concentration in the last solution.

The Fratini test, found in the European regulations (EN 196-5 standard) for pozzolanic cements $[23,24]$, was used to assess the pozzolanicity of the studied systems. It consisted of comparing the concentration of lime in a solution containing cement with the different added percentages of the incorporated residue. In this case, as the main difference with the SLS test, the pozzolanicity test for pozzolanic cements in contact with distilled water was evaluated. Pozzolanic cements are a consequence of the incorporation of feldspar in the partial replacement of cement. The methodology was as follows. Twenty grams of the material was mixed with $100 \mathrm{~mL}$ of distilled and decarbonated water. The mixture was stirred vigorously to homogenize as much material as possible and kept in an oven at $40{ }^{\circ} \mathrm{C}$. The test ages included in the regulations were 8 and 15 days. After the reaction periods, the filtered solution was analogously compared to the method used to determine the pozzolanic activity by SLS. 
Mechanical behavior was determined in mortars with a MICROTEST universal testing machine (Microtest, Madrid, Spain). Three samples of each mortar were measured at different curing ages. Total density was found with gas displacement with a ACCUPYC 1330 helium pycnometer (Micromeritics, Norcross, GA, USA).

The Böhme machine (Ibertest, Madrid, Spain) test was used to perform the abrasive test on the mortars in accordance with the UNE-EN 13892-3 standard. The tests were performed at room temperature. Brown fused alumina $\left(\mathrm{Al}_{2} \mathrm{O}_{3}\right)$ was used as an abrasive material, and the applied load was $294 \mathrm{~N}$. Three samples of each mortar were tested. As the standard suggests, the thickness reduction was measured. Mass loss in each sample was measured, and volume loss was determined according to Equation (1).

$$
A=\Delta \mathrm{V}=\frac{\Delta \mathrm{m}}{\rho R}
$$

where $\Delta \mathrm{V}$ is the total volume lost in $\mathrm{cm}^{3}$ after 16 cycles, $\Delta \mathrm{m}$ is the mass lost after 16 cycles and $\rho_{R}$ is the mortar density [25]. The morphology of the wear track after the wear test was characterized by a DSX500 profilometer (Olympus Corporation, Tokyo, Japan).

\section{Results and Discussion}

\subsection{Mineralogical Characterization of Raw Materials}

Figure 1 shows the mineralogical characterization of all the raw materials using FTIR and XRD. Regarding the most significant FTIR results, the presence of an intense band located around ca. 800-1000 $\mathrm{cm}^{-1}$ is observed in all materials, which is attributed to the presence of $\mathrm{SiO}_{4}$ groups, specifically to asymmetric tensions of the $\mathrm{O}-\mathrm{Si}-\mathrm{O}$ bonds [8]. If the position of this band is compared among materials, it is possible to observe notable differences. In the waste corresponding to blast furnace slag, this band lies at around $900 \mathrm{~cm}^{-1}$. However, in the case of fly ash and both ceramic wastes, it appears slightly above $1000 \mathrm{~cm}^{-1}$. This is because all the materials are aluminosilicates, but fly ash and ceramic wastes have a higher aluminum content, causing the band to shift toward a higher wavenumber. The presence of characteristic bands related to the presence of carbonates, around ca. $1400 \mathrm{~cm}^{-1}$, should also be noted. This band can be found in CEM I, blast furnace slag and porous ceramic residue, mainly due to the high $\mathrm{CaO}$ content it presents. The $\mathrm{CaO}$ content with the presence of ambient $\mathrm{CO}_{2}$ and humidity causes the formation of calcite-type carbonates $\left(\mathrm{CaCO}_{3}\right)$. In the $\mathrm{CEM} \mathrm{I} \mathrm{system,} \mathrm{the} \mathrm{band} \mathrm{corresponding}$ to the presence of sulfates $\left(\mathrm{SO}_{4}{ }^{2-}\right)$ is observed, located at around $1100-1200 \mathrm{~cm}^{-1}$, which is attributed to asymmetric stress vibrations.

Regarding the different diffractograms presented (Figure 1b), clear differences can be observed for each of the studied materials. In the case of CEM I, the presence of numerous crystalline phases is observed, such as calcium silicates, $\mathrm{C}_{3} \mathrm{~S}$ and $\mathrm{C}_{2} \mathrm{~S}$ (alite and belite), as well as some reaction products generated after the slight hydration that the cement underwent due to its atmospheric exposure [26]. In the diffractogram corresponding to the blast furnace slag, a halo is present between the values of $2 \theta=25-35^{\circ}$ due to the fact that the material is quite amorphous. Fly ash, on the other hand, has a somewhat higher crystallinity since crystalline phases of quartz $\left(\mathrm{Q}, \mathrm{SiO}_{2} ; \mathrm{PDF}\right.$ card 331161) and mullite $\left(\mathrm{M}, \mathrm{Al}_{6} \mathrm{Si}_{2} \mathrm{O}_{13}\right.$; PDF card 150776) appear. Finally, the diffractogram corresponding to the ceramic residues (porcelain and porous) shows a similar mineralogical behavior, with the presence of quartz (Q, $\mathrm{SiO}_{2} ; \mathrm{PDF}$ card 331161) and mullite $\left(\mathrm{M}, \mathrm{Al}_{6} \mathrm{Si}_{2} \mathrm{O}_{13} ; \mathrm{PDF}\right.$ card 150776). Different feldspars, such as sodium feldspar (albite, $\mathrm{A}, \mathrm{NaAlSi}_{3} \mathrm{O}_{8}$; $\mathrm{PDF}$ card 190926), and traces of diopside $\left(\mathrm{D}, \mathrm{CaMg}\left(\mathrm{SiO}_{3}\right)_{2}\right.$; PDF card 190239) are also identified [11]. 

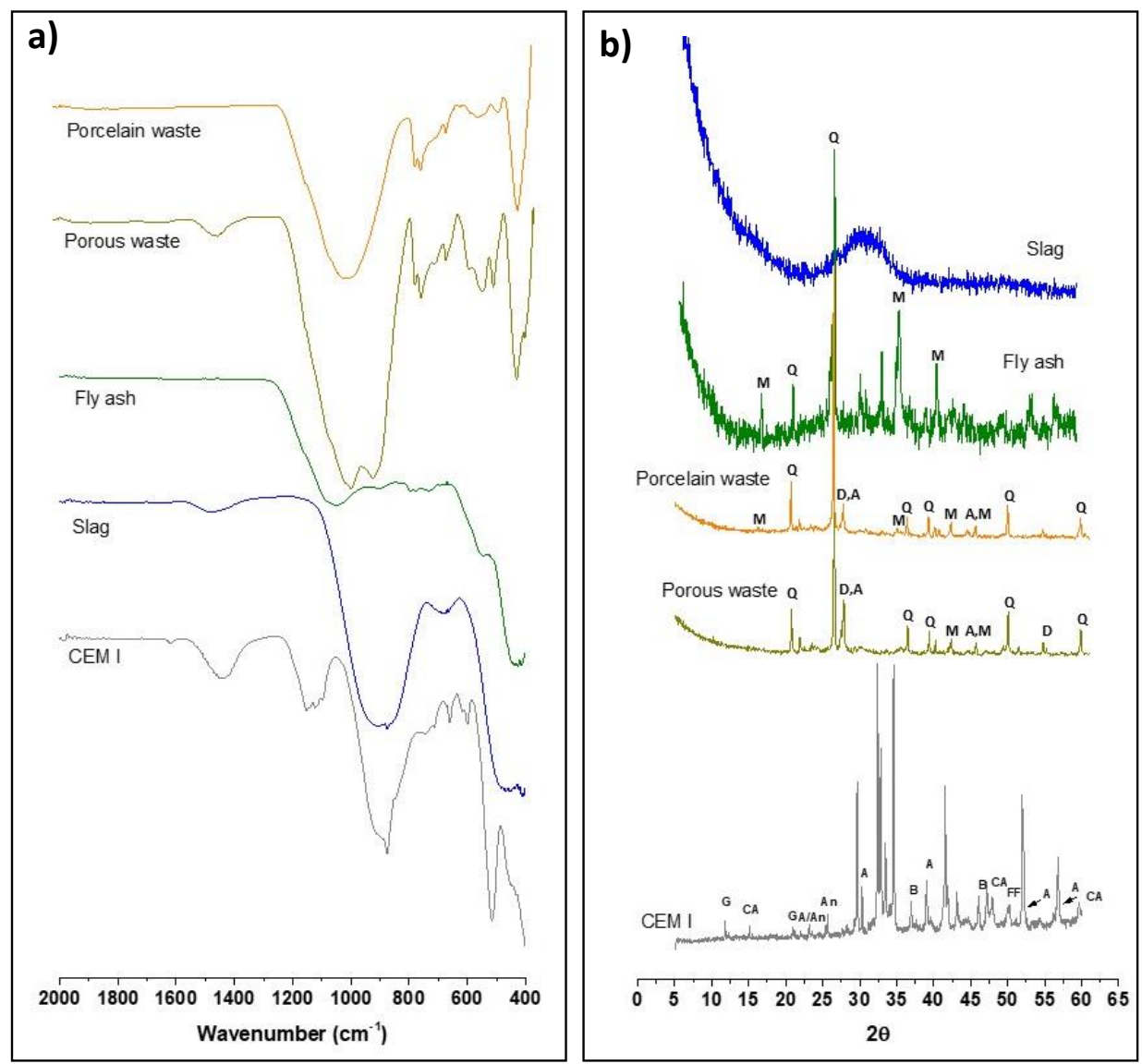

Figure 1. (a) FTIR spectra region between 2000 and $400 \mathrm{~cm}^{-1}$ and (b) XRD diffractogram of different materials used (Portland cement (CEM I), slag, fly ash, porous waste, and porcelain waste). The diffractogram corresponding to $C E M I$ presents different crystalline phases $\left(\mathrm{G}=\right.$ gypsum; $\mathrm{CA}=\mathrm{C}_{3} \mathrm{~A}$; $\mathrm{An}=$ anhydre; $\mathrm{A}=\mathrm{C}_{3} \mathrm{~S} ; \mathrm{B}=\mathrm{C}_{2} \mathrm{~S} ; \mathrm{FF}=\mathrm{C}_{4} \mathrm{AF}$; the diffractogram corresponding to porous and porcelain waste presents different crystalline phases $\left(\mathrm{Q}=\right.$ quartz; $\mathrm{M}=$ mullite; $\mathrm{D}=\mathrm{CaMg}\left(\mathrm{SiO}_{3}\right)_{2} ; \mathrm{A}=\mathrm{NaAlSi}_{3} \mathrm{O}_{8}$.

\subsection{Pozzolanic Properties of Raw Materials}

Figure 2a shows the percentages of the lime fixation of each of the residues studied at curing ages of 1, 7, 14, 21 and 28 days. After the first day of reaction, all the residues show similar results, but after seven days, clear differences are observed since this is when the chemical and mineralogical compositions present a greater influence on the reaction kinetics. It can be seen that ceramic wastes, both porous and porcelain, have a high capacity to fix calcium hydroxide from relatively short reaction times [13]. After 14 days of reaction, both materials show values around $90 \%$. These values are also very high compared to the fixation percentages presented by both fly ash and slag. Slag particularly has the lowest lime fixation, reaching $50 \%$ after 28 days of reaction. Observing the chemical compositions (Table 1), it is concluded that higher contents of acidic oxides, such as $\mathrm{SiO}_{2}, \mathrm{Al}_{2} \mathrm{O}_{3}$ and $\mathrm{Fe}_{2} \mathrm{O}_{3}$, lead to greater pozzolanic activity $[11,13,23]$. 

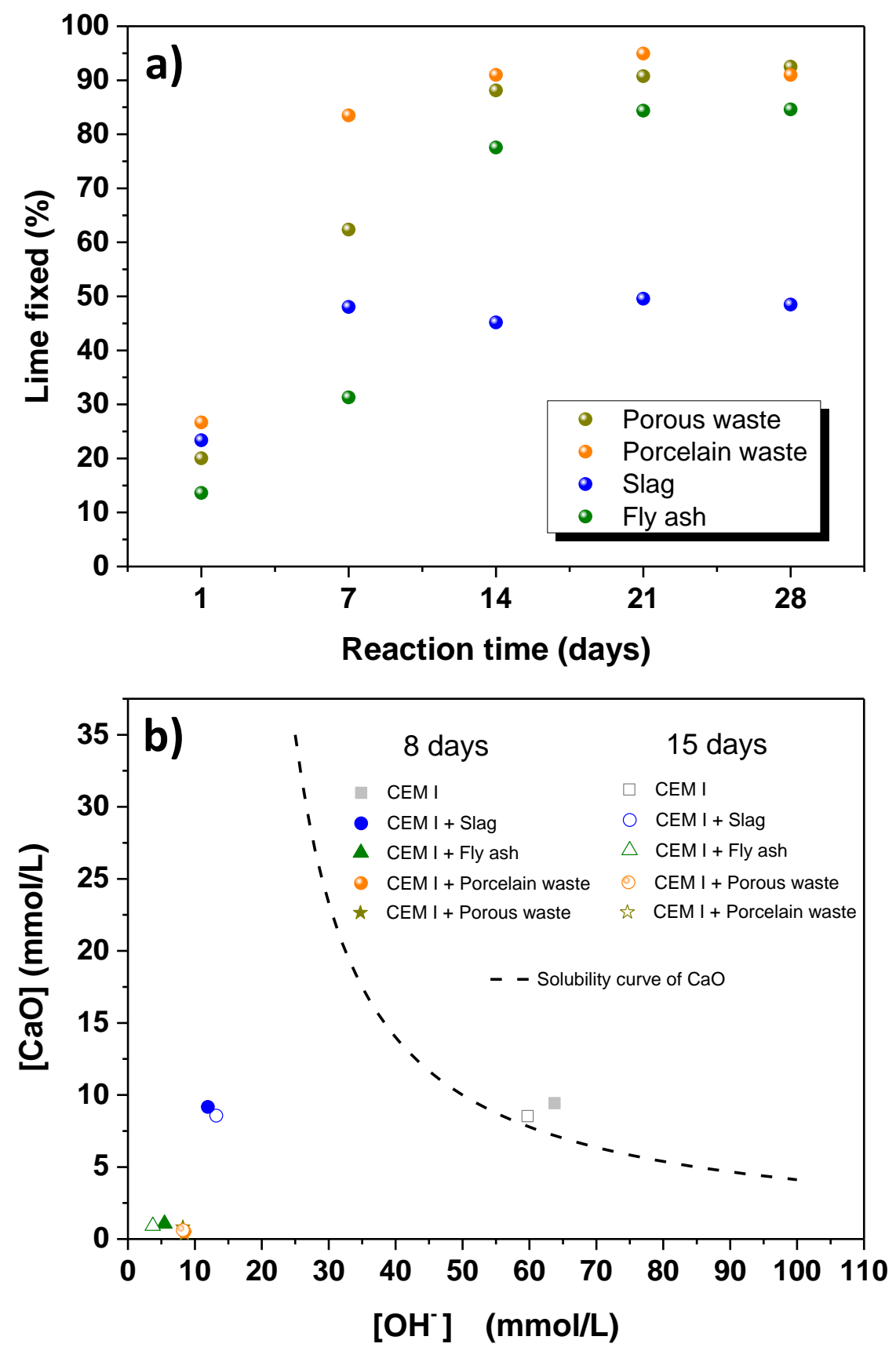

Figure 2. (a) Lime fixed to different wastes used in this study over time (1, 7, 14, 21 and 28 days); (b) pozzolanicity test for studied cement paste compositions at 8 days (filled symbols) and 15 days (hollow symbols).

According to the results obtained from the pozzolanic activity of each of the used raw materials, different mixtures of hybrid systems (without $\mathrm{Na}_{2} \mathrm{SO}_{4}$ ) were prepared with $80 \mathrm{wt} \%$ of slag, fly ash, porous waste or porcelain waste and $20 \mathrm{wt} \%$ of CEM I. The pozzolanic activity of these systems was evaluated using the Fratini test. According to European Standard 197-1, for a cement type to be considered a pozzolanic material, it must comply with the $\mathrm{CaO}$ solubility point below the calcium oxide saturation concentration curve for a period of 8 days or after 15 days. In all cases, the hybrid cement compositions comply with it at seven days, indicating pozzolanic behavior (Figure 2b). Therefore, regardless of the type, it can be concluded that all of the residues can be used as suitable cementitious materials. 


\subsection{Mechanical Behavior and Total Porosity}

Figure 3 shows the results obtained after the hydration process for each of the evaluated systems and a comparison with the reference system (CEM I) at different curing ages (1, 7 and 28 days). In the case of CEM I (Figure 3a), it is observed how, as the hydration times increase, the compression also strength increases. This is due to the hydration process of the cement and the progressive formation of the C-S-H gel as well as secondary reaction products, such as portlandite or ettringite, among others, achieving final strengths at 28 days of curing around $45 \mathrm{MPa}[26,27]$.
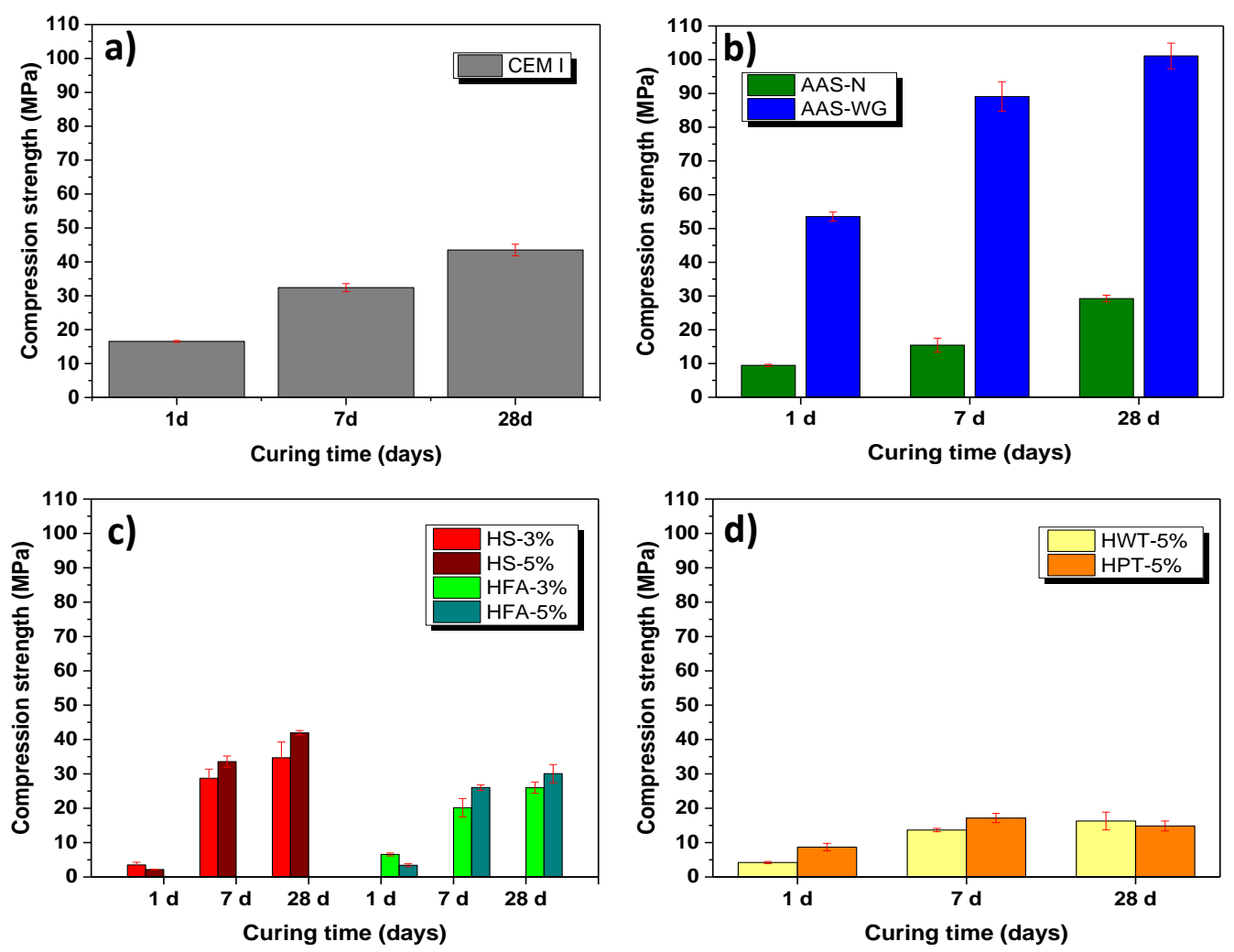

Figure 3. Compression strengths of mortars at different curing ages (1, 7 and 28 days): (a) Portland cement (CEM I); (b) alkaline-activated slag with $4 \mathrm{M} \mathrm{NaOH}$ (AAS-N) and with sodium silicate solution (AAS-WG); (c) hybrids cements with blast furnace slag (HS-3\% and HS-5\%) and with fly ash (HFA-3\% and HFA-5\%); (d) hybrid cements with porous waste (HWT) and with porcelain waste (HPT).

Figure $3 \mathrm{~b}$ shows the mechanical behavior of alkaline-activated slag systems activated with $\mathrm{NaOH}$ and sodium silicate (waterglass). As with the CEM I system, as the curing time increases, the mechanical strength also increases regardless of the activator used. However, there is a clear difference between the use of $\mathrm{NaOH}$ and sodium silicate. By using an activator with silicon in its composition, a much more compact and cohesive C-A-S-H gel is produced, promoting very high resistance [8,28]. At the age of 28 days, compression strength values greater than $100 \mathrm{MPa}$ are reached. On the other hand, regarding the activation of the slag with $\mathrm{NaOH}$, it is possible to observe that the results at 28 days are much lower than those obtained with the use of sodium silicate (compression strengths of around $30 \mathrm{MPa}$ ), presenting, therefore, a difference of around $70 \%$ between both alkaline activators.

Regarding the manufactured hybrid systems, Figure $3 \mathrm{c}$ shows the mechanical behavior of the hybrid slag and the hybrid fly ash mortars, all of which were prepared with $3-5 \% \mathrm{Na}_{2} \mathrm{SO}_{4}$ as an alkaline source. At short curing ages, it is observed that the hybrid cement with fly ash presents slightly higher strengths, but, as the curing time increases, the hybrid systems made of slag show better mechanical behavior. This is due to the fact that, in the case of slag, as hydration takes place at room temperature, the calcium present in the composition begins to dissolve and reacts with silicon to form the main 
reaction product, the C-A-S-H gel. However, since no activating solutions are added in this case, these gels are less rich in silicon and, therefore, lower mechanical strengths are obtained than those obtained for alkali-activated cements (Figure 3b). In addition, for the hybrid systems composed of fly ash, the results are noticeably inferior because, unlike slag, the ash needs a temperature input in the system to dissolve and generate the zeolites, which are the precursors of the main product reaction in the activation of the ashes (N-A-S-H gel). Regarding the addition of different percentages of $\mathrm{Na}_{2} \mathrm{SO}_{4}$, mortars composed of $5 \% \mathrm{Na}_{2} \mathrm{SO}_{4}$ obtain slightly higher mechanical performance at longer curing times. At the age of 28 days, for the hybrid slag systems at $5 \% \mathrm{Na}_{2} \mathrm{SO}_{4}$ resistance, values are obtained around $42 \mathrm{MPa}$, whereas the hybrid ash systems at $5 \% \mathrm{Na}_{2} \mathrm{SO}_{4}$ presented results of $30 \mathrm{MPa}$ at 28 days of curing.

Finally, Figure $3 \mathrm{~d}$ shows the results of the hybrid systems manufactured with the ceramic industry wastes (HWT and HPT). The results show that the compression strength is lower than all the systems previously presented. The resistance increases as the curing time increases but up to a limit since, at the age of 28 days, it is observed that they are very similar to those obtained after seven days of hydration. This behavior is due to the fact that both ceramic residues present a composition with a low $\mathrm{CaO}$ content similar to that of fly ash. This phenomenon is important since the dissolution and activation processes of these residues are quite similar to the hydration mechanisms of fly ashes (a thermal input is needed to favor the formation of zeolitic precursors). The heat released during hydration in these hybrid systems is not enough for the appropriate formation of the N-A-S-H gel and perhaps, in these systems, to achieve better mechanical performance, it is necessary to increase the percentage of CEM I in their composition.

From the point of view of the total porosity of these systems, Figure 4 shows the relationship between porosity at 28 days of curing and the mechanical strengths obtained. Observing the results, it can be seen that AAS-WG has lower percentages of porosities than the CEM I reference system. In this sense, the systems activated with $\mathrm{NaOH}$ present a total porosity of around $11.5 \%$ whereas the mortars activated with sodium silicate present a total porosity of around $2 \%$. This is due to the formation of the C-A-S-H gel in both systems and the AAS-WG gel being richer in silicon, which allows a more compact and cohesive gel to be formed, thus promoting a very high compression strength [8,29]. In relation to the hybrid systems, the fly ash systems also show high percentages of total porosity between 8 and $13 \%$. The HFA-3\% system presents the highest porosity, which is directly proportional to the low compression strength achieved. The hybrid ash system at $5 \% \mathrm{Na}_{2} \mathrm{SO}_{4}$ (HFA-5\%) achieves slightly lower porosity values. This fact is indicative of the extra supply of $\mathrm{Na}_{2} \mathrm{SO}_{4}$ (that increases the alkalinity of the system), thus favoring the precipitation of the main reaction products. However, the hybrid systems made of $80 \mathrm{wt} \%$ slag (HS-3\% and HS-5\%) present low total porosity values, such as the system with $5 \%$ of $\mathrm{Na}_{2} \mathrm{SO}_{4}$, which seems to present a more uniform gel and adopts greater compactness to the system. Finally, regarding hybrid mortars from ceramic residues (HWT-5\% and HPT-5\%), it is observed that the total porosity is very similar to the HFA-3\% system, indicating that, at room temperature, the hydration reaction of the aluminosilicates (with a low content of $\mathrm{CaO}$ ) has not been completed to give the main reaction product, N-A-S-H gel.

\subsection{Durability to Wear: Böhme Test}

The reactivity (pozzolanicity) of the studied materials exerts an important effect on the formation of gels, thus leading to the evaluated porosities and mechanical strength. Moreover, they are important in understanding the abrasion performance of the proposed alkali-activated materials and hybrid systems after 28 days of curing.

Figure $5 \mathrm{a}, \mathrm{b}$ shows the height and volume losses of each system, respectively, evaluated after the wear test of mortars at the age of 28 days. Results from the Böhme tests are usually evaluated according to height loss (Figure 5a). It is worth highlighting the behavior of AAS-WG, with about half of the height loss than CEM I. This excellent performance can be clearly understood, taking into account the highest strength and lowest porosity of AAS-WG (Figure 4). Moreover, the other alkali-activated material 
(AAS-N) and hybrid materials manufactured from slag (HS-3\% and HS-5\%) also lost less height than CEM I. These materials are slightly less strong, and their porosity is similar to CEM I (Figure 4). However, the positive compactness of their gels (C-S-H and C-A-S-H) seems to play an important role in the adhesion of sand particles and on the performance of these materials. Hybrid materials with fly ash and ceramic wastes lost more thickness than CEM I, probably related to their higher porosity and less strength (Figure 4) due to the previously explained lack of formation of N-A-S-H gel.

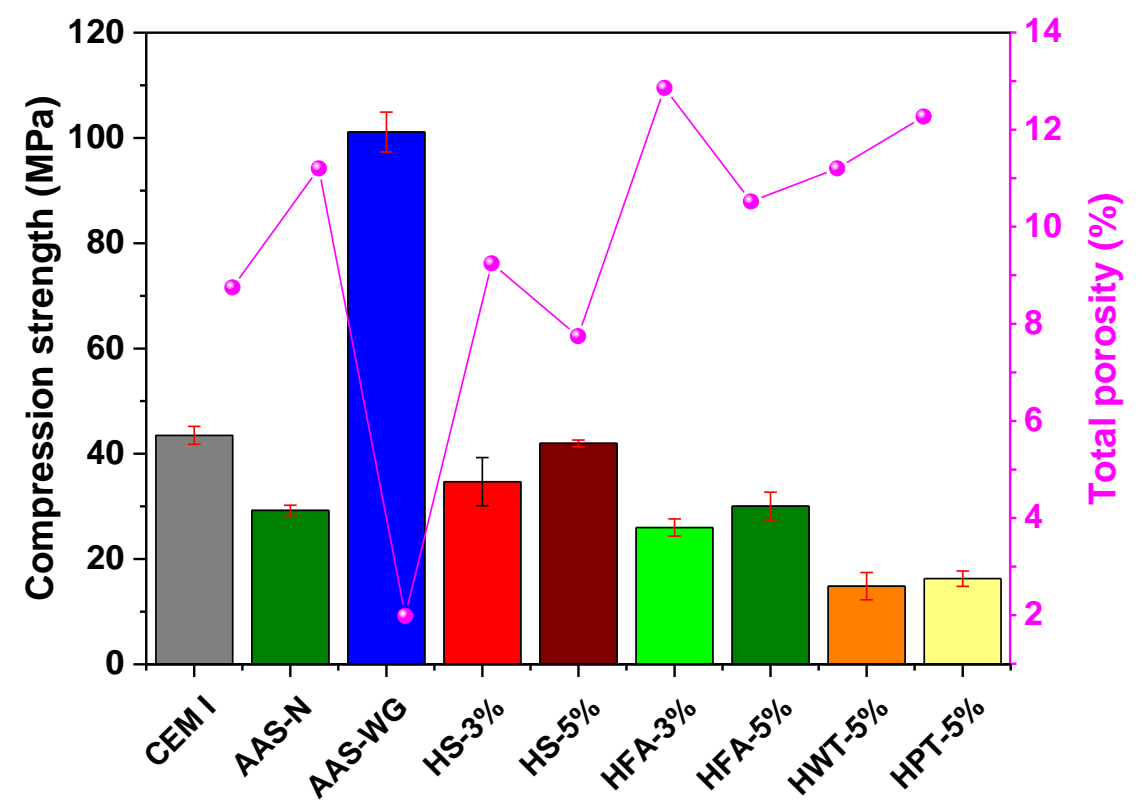

Figure 4. Relationship between compression strength and total porosity at 28 days of curing for all systems evaluated.

From the results of the mass loss and density of each mortar (Table 4), the volume loss of each system after the wear test was also calculated, highlighting the results in Figure 5b. There are slight changes in the trends in comparison to those observed for height loss (Figure 5a). Difference between both measurements can be mainly related to the detachment of sand particles, which affect mass loss more than height. The fact that the abrasion performance of AAS-N worsens can be related to the lower adhesion of sand particles to the C-A-S-H gel than to C-S-H of CEM I. This effect can also be appreciated in AAS-WG. The excellent results of AAS-WG agree with the positive effect of using sodium silicate as an activator found in the literature, being able to promote better abrasion resistances than CEM I Portland cement [30], which does not occur with other activators such as $\mathrm{NaOH}$. Both slag-containing hybrid mortars show improved results of volume loss compared to height, where CEM I is taken as a reference for analysis. This indicates that the positive effect of both gels and using $5 \%$ of $\mathrm{Na}_{2} \mathrm{SO}_{4}$ promotes the best results (wear improvement was around $42 \%$ compared to the CEM I system) as the compactness of the gel is improved (previously found in other properties, Figure 4). In addition, observing the results obtained on porosities, a clear relationship between these parameters is presented since, in general, materials with higher porosities have shown greater volume losses [20]. It should be noted that the hybrid mortar with porcelain waste (HPT-5\%), though it did not obtain a high mechanical resistance, showed a notable improvement in terms of durability to wear. Porcelain wastes showed a high $\mathrm{Na}_{2} \mathrm{O}$ content compared to the other proposed wastes. This difference, among other factors, causes this residue to present different results in terms of durability behavior. However, on the other hand, it is important to highlight that the alkaline-activated system with $\mathrm{NaOH}$ (AAS-N) presented good mechanical behavior, but after the Böhme test, it was among the systems that presented the worst performance. As studied in previous works [20], using alkaline solutions that 
present efflorescence phenomena means that after wear with a counter material, there is a greater loss of mass and a greater wear mark is generated.
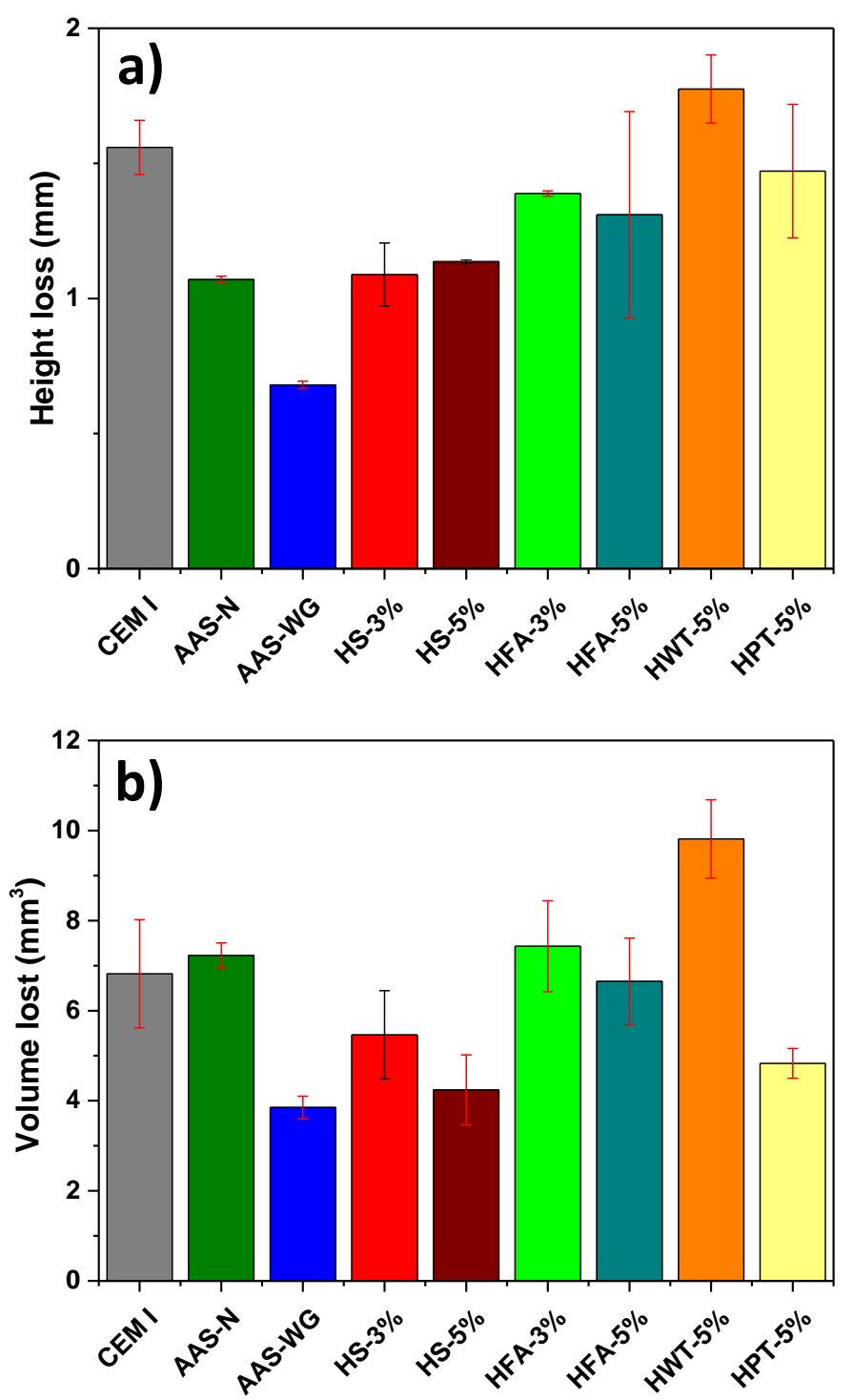

Figure 5. (a) Height loss in different mortars studied after wear test; (b) lost volume after the wear test (Böhme test) in all systems evaluated.

Table 4. Density of all systems evaluated at 28 days.

\begin{tabular}{cc}
\hline System & Density $\left(\mathrm{g} / \mathrm{cm}^{3}\right)$ \\
\hline CEM I & $2.51 \pm 0.0066$ \\
AAS-N & $2.49 \pm 0.0021$ \\
AAS-WG & $2.52 \pm 0.0021$ \\
HS-3\% & $2.56 \pm 0.0072$ \\
HS-5\% & $2.54 \pm 0.0051$ \\
HFA-3\% & $2.64 \pm 0.0025$ \\
HFA-5\% & $2.64 \pm 0.0069$ \\
HWT-5\% & $2.56 \pm 0.0075$ \\
HPT-5\% & $2.51 \pm 0.0012$ \\
\hline
\end{tabular}


It has previously been stated that the abrasion resistance of mortars improves with increasing strength (flexural or compression) and compactivity [31], and fly ash and slag can enhance the abrasion resistance of concretes when they replace fine aggregates [32,33]. To understand the performance of hybrid mortars, the relationship between their compression strength and lost volume is shown in Figure 6. The linear relationship previously found by other authors for traditional mortars [31] is found for hybrid materials, highlighting the importance of mechanical strength on abrasion resistance. It can be appreciated how HS-5\% presents less abrasion for almost the same strength than CEM I. Moreover, the performance of HPT-5\%, which presents very low abrasion with very low strength, is worth mentioning. The $\mathrm{Na}_{2} \mathrm{O}$ content of its composition (Table 1) might provide a very hard gel that reduces the compression strength of the material due to its brittleness (Figure 4) and is able to withstand abrasion in a very noticeable way (Figures $5 b$ and 6 ).

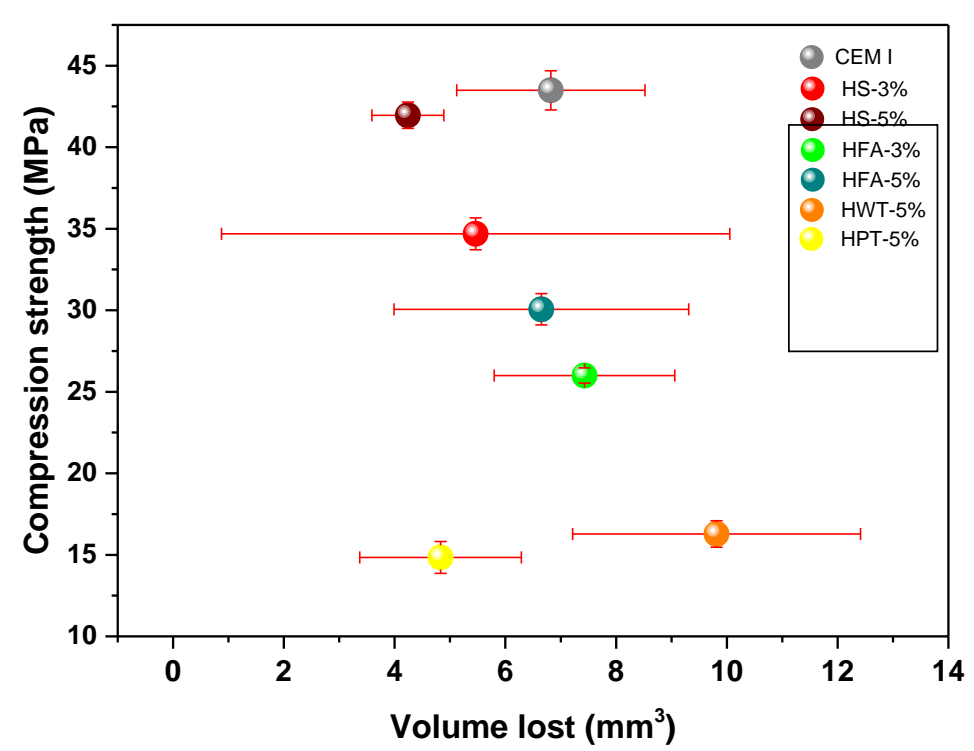

Figure 6. Effect of compression strength of hybrid mortars on the lost volume $\left(\mathrm{mm}^{3}\right)$ after the Böhme test.

To complete this study, each sample was analyzed after the Böhme test with a profilometer to find a correlation with the rest of the properties determined. In Figure 7, it is possible to observe the different wear tracks that each evaluated system (CEM I, HS-5\%, HFA-5\%, HPT-5\% and HWT-5\%) presents. By using this technique, we were not able to obtain clear information regarding the different mechanisms that took place during the wear process. Almost flat surfaces can be observed, typical of an abrasion process taking place on all the surfaces. Any effect at the microstructural level cannot be inferred, and only the detachment of sand particles can clearly be appreciated. Moreover, voids left by detached sand particles seem to be refilled with the debris formed during the abrasion process in all studied materials. 

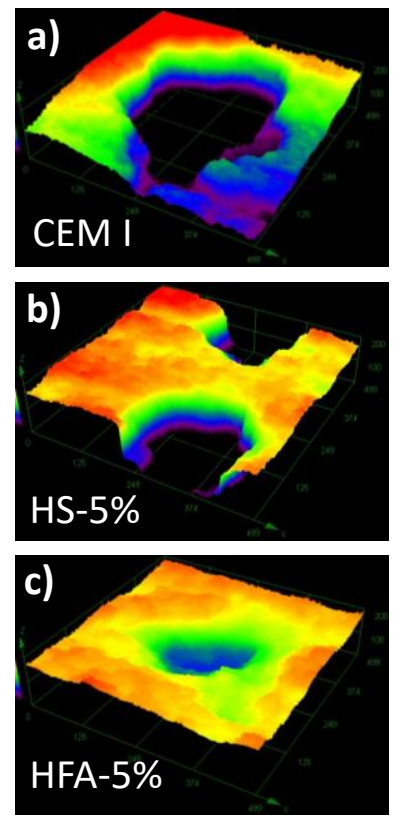
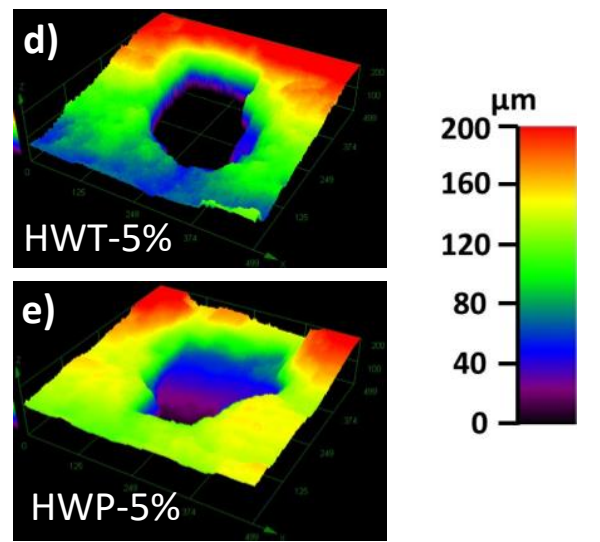

Figure 7. Profilometry 3D image of representative worn surfaces after the Böhme test of (a) CEM I, (b) HS-5\%, (c) HFA-5\%, (d) HWT-5\% and (e) HWP-5\%.

\section{Conclusions}

The main purpose of this work was the study of possible alternative materials to Portland cement to obtain more sustainable and durable cementitious materials. The most important conclusions that can be drawn from this study are the following:

- All the residues used in this work show pozzolanic behavior (SLS and Fratini tests) and have good capacities for the manufacturing of alternative cements. The residues from the ceramic industry are those with the greatest pozzolanic character.

- Silicate-activated slag systems (AAS-WG) present the best mechanical performance, but hybrid mortars present an important alternative, obtaining competitive results.

- Ceramic waste hybrid mortars show worse mechanical resistance results. It is necessary to increase the percentage of CEM I to improve the hydration process.

- Most of the alternative hybrid systems proposed showed an improvement in durability to abrasion compared to Portland cement (CEM I), highlighting the behavior of AAS-WG and HS-5\%.

Therefore, it can be concluded that these alternative systems to Portland cement (both alkaline-activated and hybrid mortars) show adequate behavior from a mechanical and durable point of view, thus opening a gate to development and industrial implementation in the construction sector.

Author Contributions: Conceptualization, M.T.-C., S.S., L.R., and F.V.; methodology, M.T.-C., S.S. and L.R.; validation, M.T.-C., S.S., L.R., A.B., M.F.-Á. and F.V.; formal analysis, M.T.-C., S.S., L.R., A.B., M.F.-Á. and F.V.; investigation, M.T.-C., S.S., L.R., A.B. and F.V.; writing—original draft preparation, M.T.-C., S.S., L.R., A.B., M.F.-Á. and F.V.; writing-review and editing, M.T.-C., S.S., L.R., A.B., M.F.-Á. and F.V.; visualization, M.T.-C., S.S., L.R., A.B., M.F.-Á. and F.V.; supervision, M.T.-C., A.B. and F.V.; project administration, M.T.-C., A.B. and F.V.; funding acquisition, M.T.-C., A.B. and F.V. All authors have read and agreed to the published version of the manuscript.

Funding: This word was founded by the Ministerio de Ciencia, Innovación y Universidades of Spain through the project RTI2018-096428-B-I00 and by the regional project of Comunidad de Madrid, HORATSO- UC3M-CM.

Acknowledgments: This study was funded by the Ministerio de Ciencia, Innovación y Universidades of Spain through project RTI2018-096428-B-I00 and through regional project HORATSO-UC3M-CM.

Conflicts of Interest: The authors declare no conflict of interest. 


\section{References}

1. Andrew, R.M. Global $\mathrm{CO}_{2}$ emissions from cement production. Earth Syst. Sci. Data 2017, 1-52. [CrossRef]

2. Bernal, E.; Edgar, D.; Burnes, B. Building Sustainability on Deep Values Through Mindfulness Nurturing. Ecol. Econ. 2018, 146, 645-657. [CrossRef]

3. Alrefaei, Y.; Wang, Y.S.; Dai, J.G. The effectiveness of different superplasticizers in ambient cured one-part alkali activated pastes. Cem. Concr. Compos. 2019, 97, 166-174. [CrossRef]

4. Fořt, J.; Černý, R. Transition to circular economy in the construction industry: Environmental aspects of waste brick recycling scenarios. Waste Manag. 2020, 118, 510-520. [CrossRef] [PubMed]

5. Açıkkalp, E.; Hepbasli, A.; Yucer, C.T.; Karakoc, T.H. Advanced life cycle integrated exergoeconomic analysis of building heating systems: An application and proposing new indices. J. Clean. Prod. 2018, 195, 851-860. [CrossRef]

6. Torres-Carrasco, M.; Puertas, F. La activación alcalina de diferentes aluminosilicatos como una alternativa al Cemento Portland: Cementos activados alcalinamente o geopolímeros. Rev. Ing. Constr. 2017, 32, 5-12. [CrossRef]

7. Torres-Carrasco, M.; Puertas, F. Waste glass in the geopolymer preparation. Mechanical and microstructural characterisation. J. Clean. Prod. 2015, 90, 397-408. [CrossRef]

8. Puertas, F.; Torres-Carrasco, M. Use of glass waste as an activator in the preparation of alkali-activated slag. Mechanical strength and paste characterisation. Cem. Concr. Res. 2014, 57, 95-104. [CrossRef]

9. Mikhailova, O.; del Campo, A.; Rovnanik, P.; Fernández, J.F.; Torres-Carrasco, M. In situ characterization of main reaction products in alkali-activated slag materials by Confocal Raman Microscopy. Cem. Concr. Compos. 2019, 99, 32-39. [CrossRef]

10. Nwankwo, C.O.; Bamigboye, G.O.; Davies, I.E.E.; Michaels, T.A. High volume Portland cement replacement: A review. Constr. Build. Mater. 2020, 260, 120445. [CrossRef]

11. Pitarch, A.M.; Reig, L.; Tomás, A.E.; Forcada, G.; Soriano, L.; Borrachero, M.V.; Payá, J.; Monzó, J.M. Pozzolanic activity of tiles, bricks and ceramic sanitary-ware in eco-friendly Portland blended cements. J. Clean. Prod. 2021, 279. [CrossRef]

12. Samadi, M.; Huseien, G.F.; Mohammadhosseini, H.; Lee, H.S.; Abdul Shukor Lim, N.H.; Tahir, M.M.; Alyousef, R. Waste ceramic as low cost and eco-friendly materials in the production of sustainable mortars. J. Clean. Prod. 2020, 266, 121825. [CrossRef]

13. Enríquez, E.; Torres-Carrasco, M.; Cabrera, M.J.; Muñoz, D.; Fernández,J.F. Towards more sustainable building based on modified Portland cements through partial substitution by engineered feldspars. Constr. Build. Mater. 2020, 121334. [CrossRef]

14. Torres-Carrasco, M.; Enríquez, E.; Terrón-menoyo, L.; Cabrera, M.J.; Muñoz, D.; Fernández, J.F. Improvement of thermal efficiency in cement mortars by using synthetic feldspars. Constr. Build. Mater. 2020, 121279. [CrossRef]

15. Bernal, S.A.; Mejía de Gutiérrez, R.; Ruiz, F.; Quiñones, H.; Provis, J.L. Desempeño a temperaturas altas de morteros y hormigones basados en mezclas de escoria/metacaolín activadas alcalinamente. Mater. Constr. 2012, 62, 471-488. [CrossRef]

16. Fu, Y.; Cai, L.; Yonggen, W. Freeze-thaw cycle test and damage mechanics models of alkali-activated slag concrete. Constr. Build. Mater. 2011, 25, 3144-3148. [CrossRef]

17. Gifford, P.M.; Gillott, J.E. Freeze-thaw durability of activated blast furnace slag cement concrete. ACI Mater. J. 1996, 93, 242-245.

18. Torres-Carrasco, M.; Tognonvi, M.; Tagnit-Hamou, A.; Puertas, F. Durability of Alkali-Activated Slag Concretes Prepared using waste glass as Alternative activator. ACI 2015, 112, 791-800.

19. Shi, C.; Jiménez-Fernández, A.; Palomo, A. New cements for the 21st century: The pursuit of an alternative to Portland cement. Cem. Concr. Res. 2011, 41, 750-763. [CrossRef]

20. Shagñay, S.; Velasco, F.; del Campo, A.; Torres-Carrasco, M. Wear behavior in pastes of alkali-activated materials: Influence of precursor and alkali solution. Tribol. Int. 2020, 147. [CrossRef]

21. Lam, M.N.T.; Le, D.H.; Jaritngam, S. Compressive strength and durability properties of roller-compacted concrete pavement containing electric arc furnace slag aggregate and fly ash. Constr. Build. Mater. 2018, 191, 912-922. [CrossRef] 
22. Asociación Española de Normalización y Certificación, EN 196-5. Method of Testing Cement. Part 5: Pozzolanicity Test for Pozzolanic Cement; AENOR: Madrid, Spain, 2011.

23. Asensio, E.; Medina, C.; Frías, M.; de Rojas, M.I.S. Characterization of Ceramic-Based Construction and Demolition Waste: Use as Pozzolan in Cements. J. Am. Ceram. Soc. 2016, 99, 4121-4127. [CrossRef]

24. UNE-EN 196-5. Métodos de Ensayo de Cementos. Ensayo de Puzolanicidad Para Los Cementos Puzolánicos; AENOR: Madrid, Spain, 2011.

25. En, N.E.; Une-en, N. Española; AENOR: Madrid, Spain, 2016.

26. Torres-Carrasco, M.; Campo, A.; De Rubia, M.A.; Reyes, E.; Moragues, A.; Fernández, J.F. New insights in weathering analysis of anhydrous cements by using high spectral and spatial resolution Confocal Raman Microscopy. Cem. Concr. Res. 2017, 100, 119-128. [CrossRef]

27. Torres-Carrasco, M.; del Campo, A.; de la Rubia, M.A.; Reyes, E.; Moragues, A.; Fernández, J.F. In situ full view of the Portland cement hydration by confocal Raman microscopy. J. Raman Spectrosc. 2019, 50, 720-730. [CrossRef]

28. Torres-Carrasco, M.; Puertas, F. Waste glass as a precursor in alkaline activation: Chemical process and hydration products. Constr. Build. Mater. 2017, 139, 342-354. [CrossRef]

29. Puertas, F.; Torres-Carrasco, M.; Alonso, M.M. Reuse of urban and industrial waste glass as novel activator for alkali-activated slag cement pastes: A case study. In Handbook of Alkali-Activated Cements, Mortars and Concretes; Woodhead: Cambrige, UK, 2014; pp. 75-110. ISBN 9781782422884.

30. Karahan, O.; Yakupoğlu, A. Resistance of alkali-activated slag mortar to abrasion and fire. Adv. Cem. Res. 2011, 23, 289-297. [CrossRef]

31. Yetgin, S.; Çavdar, A. Abrasion Resistance of Cement Mortar with Different Pozzolanic Compositions and Matrices. J. Mater. Civ. Eng. 2011, 23, 5533. [CrossRef]

32. Bilir, T.; Yüksel, I.; Topcu, I.B.; Gencel, O. Effects of bottom ash and granulated blast furnace slag as fine aggregate on abrasion resistance of concrete. Sci. Eng. Compos. Mater. 2017, 24, 261-269. [CrossRef]

33. Sevinç, A.H.; Durgun, M.Y.; Eken, M. A Taguchi approach for investigating the engineering properties of concretes incorporating barite, colemanite, basaltic pumice and ground blast furnace slag. Constr. Build. Mater. 2017, 135, 343-351. [CrossRef]

Publisher's Note: MDPI stays neutral with regard to jurisdictional claims in published maps and institutional affiliations.

(C) 2020 by the authors. Licensee MDPI, Basel, Switzerland. This article is an open access article distributed under the terms and conditions of the Creative Commons Attribution (CC BY) license (http://creativecommons.org/licenses/by/4.0/). 